\title{
New Product Development and Disciplined Experimentation
}

\author{
Davide Sola ${ }^{*}$, Giovanni Scarso Borioli ${ }^{* *}$, Gianfranco Scalabrini ${ }^{* * *}$
}

\begin{abstract}
The process of developing new products always contains an element of uncertainty. This uncertainty translates into a significant risk for companies investing in the development of new products or services.

The risk in new product development (NPD) can be based on 'disciplined experimentation': a structured process designed to rapidly identify the 'vivid' needs of the customer, test whether the main features of the new product or service will satisfy these needs (fast prototyping).

'Disciplined experimentation', in particular, addresses assumptions about value (how the initiative will produce outcomes that outweigh the effort involved), growth (how the initiative can be scaled up beyond the first group of customers) and sustainability (how quickly the organisation can adapt to the new initiative and how easily competitors will be able to replicate it).
\end{abstract}

Keywords: Design Management; New Product Development; Product Engineering; Disciplined Experimentation; Fast Fashion Manufacturing; Heating Systems Manufacturing; Global Competition

\section{New Product Development Literature}

New product development (NPD) is an inherently uncertain process. Research shows that as many as $40 \%$ of new products fail to deliver anything approaching the promised objectives (Castellion, Markham 2013).

This uncertainty results from many factors including the difficulty of identifying 'vivid' (strong and conscious) customer needs, the problem of correctly defining the right features and shaping how the user experiences the new product or service, identifying the most suitable route to market and, of course, getting the pricing right. All these challenges must be overcome in an environment where there is increasing competitive pressure to deliver cheaper, faster and better (Brondoni 2008).

\footnotetext{
*Associate Professor of Strategy, ESCP Europe, London (dsola@escpeurope.eu)

**Assistant Professor of Operation Management, ESCP Europe, London (gscarsoborioli@ecspeurope.eu)

*** Affiliate Professor of Business Operations, ESCP Europe, London (gscalabrini@escpeurope.eu)

Edited by: ISTEI - University of Milan-Bicocca ISSN: $1593-0319$

Sola Davide, Scarso Borioli Giovanni, Scalabrini Gianfranco (2015) New Product Development and Disciplined Experimentation, Symphonya. Emerging Issues in Management (symphonya.unimib.it), n. 2, pp. $105-119$.

http://dx.doi.org/10.4468/2015.2.08sola.scarsoborioli.scalabrini
} 
To examine the issue of reducing uncertainty in new product development, we first undertook a review of the existing literature in order to establish the factors which determine success or failure in this area.

New product development can be defined as the processes employed by a business to identify, design, create and bring to market new products or services (Brondoni 2009). But what processes should be used? And which of these are critical? Research into NPD sought to identify the processes involved in order to determine which, if any, contributed to success. If those success factors could be identified, then more business should be able to carry out NPD successfully. . Early work by Hustad (1977) adopted a broad perspective when defining the NPD process and included topics such as market planning, product strategy, product line extension, market forecasting, product abandonment and product liability. Other researchers were working to refine the definitions of the NPD process into more distinct factors. An early proponent of a managed approach to NPD was Morris (Morris 1990) who had spent forty years improving project management techniques and published his influential Management of Projects theory in 1990. In the 1970s Robert Cooper and his colleagues started looking at the difficulties businesses were encountering in bringing new products to successful fruition (Cooper, Kleinschmidt 1986; 1987; 1990; 1991). As a result, they developed the NewProd project which utilised a Stage/Gate approach. This breaks the process of developing a new product into a series of stages, separated by gates or hurdles which must be passed before progressing to the next stage. Cooper identified five main aspects of the NPD process; scoping, building the business case, development, testing and validating, and product launch (Cooper 2001).

Loch (2000), while acknowledging that Stage-Gate is at the core of most NPD processes, argued that survival and growth ultimately depends on how well a company adapts to its specific environment. Davidson et al. (1999) reached a similar conclusion, emphasizing the need for flexibility so that the NPD process can be continually adjusted to an organisation's changing needs and aims.

According to Fixson (2009) most definitions of NPD include stages such as product opportunity identification, market and user analysis, idea generation, concept generation, concept refinement and selection, industrial design, prototyping, testing, financial evaluation and market introduction. Cormican and O'Sullivan (2004) saw strategy and leadership, culture and climate, planning and selection, structure and performance, and communication and collaboration as key factors. Kahn et al (2012) identified seven separate components of the NPD process; strategy (including portfolio management), process, research, project climate (including team organisation), company culture, commercialisation, metrics and performance evaluation.

Amabile (1997), Smith \& Reinertsen (1998) and DeCusatis (2008) analysed team characteristics and identified factors which can increase the creative ability of the team and help accelerate the NPD process. Thomke (2003) noted that team integration encouraged experimentation and prototyping, which Barczak, Griffin and Kahn (2009) also found was a factor of high-performing firms, suggesting this was a key factor in the NPD process.

'Fail often to succeed sooner' is reportedly one of the mottos of the successful product design firm IDEO (Kelley 2001), stressing the importance of being ready refine, cannibalise or even abandon previous ideas and assumptions. 
With the rapidly changing technological advances of the past decade there is a growing interest in the role of NPD processes that were created to handle uncertainty and changing customer needs and wants; among these new methods Agile NPD is leading the way. Agile originated in 2001 in the software development field and emphasises the importance of self managing, cross functional teams working quickly, flexibly and responsively.

\section{Critique of NPD Literature}

While all the NPD processes we reviewed have their uses in the quest to reduce risk, we noticed that they tend to share a number of pitfalls.

First, all the NPD processes featured in our literature review require extensive time and commitment if they are to be used effectively, with speed being sacrificed in favour of quality of execution. The earlier approaches to NPD focused on the need to control all aspects of the process to ensure that the development plan was completed within budget. As the pace of technological and commercial development increased, some approaches sought to adapt keep pace with the changing environment, while others did not. For example, the Management of Projects method remained static while the Stage-Gate process developed by Cooper has re-invented itself to take on board the challenges of a modern, fast paced world where technology continually forces changes in design practice and design development. More recently, Agile Development has begun to be adopted by those outside the software development arena where it was born. The flexibility of the Agile approach allows the designers and developers to take on board the fickle demands of an ever more aware customer, enabling products to better meet the customers' needs. Lean Start-up, a method proposed by Eric Reis in 2011, takes the involvement of the customer even further by encouraging continuous customer involvement from the very earliest stage of development, even as early as conception. Lean Start-up builds on the relationship with the customer to create an environment where a product could be launched well ahead of schedule, with upgrades being made available to extend the life of the product.

Design Thinking and Design of Experiments offer a different view of the NPD process. These two approaches are useful in resolving problems using unconventional means and may offer innovative insights into the development of new products and services.

However, except for the Stage-Gate process, all the other approaches assume that the right product has been selected and that the main emphasis should be on its development. And even in the case of the Stage-Gate method, one of the main problems is that businesses do not know how to ensure the gates work effectively to stop or allow progress. The tendency across all these approaches was to assume that once a particular product has entered the NPD process that this was the right product to develop. There appeared to be an inability in any of the processes to consider outside influences such as an aggressive competitor launching a similar product more quickly. Even in those processes that encourage involvement with customers, such as Lean Start-up, there was no suggestion that a product could, 
potentially, be terminated. Rather the product would be adjusted to take on the comments of the potential customers.

Another pitfall of the processes we reviewed was the lack of emphasis on encouraging ownership of the product being developed. The project team is simply presented with the product to be developed and told to get on with it. None of the processes reviewed provided much guidance on who should be involved in the 'NPD team', despite citing cross-functional teams as vital to success. The use of true cross-functional teams can improve ownership of the product being developed but this was not flagged as important. While the usefulness of experimentation is beginning to be acknowledged as a means of checking the viability of a product, it is not seen as central to the overall NPD process and, like the involvement of customers, is generally left till late in the NPD process when there is a physical product that can be handled.

The Lean Start up and Design thinking approaches, and in particular Lean Startup, have learned from the failings of previous approaches and introduced elements to overcome some of these pitfalls. Early experimentation through the construction of Minimum Viable Products (MVP's) facilitates the cost efficient testing of just one or a few variables at a time. And the introduction of the Value and Growth hypothesis requires assumptions about why customers will want the product and how they will be accessed to be made explicit and repeatedly tested. Finally the concept of Pivot has reinforced the principle that when the working hypothesis supporting a new product is found to be flawed, the product should be reconsidered and amended or abandoned completely.

\section{Research Question and Methodology}

Principles such as MVPs and the Value and Growth hypothesis represent a great advancement in the search for a robust theory of NPD. Nevertheless we believe that there are still some areas that need to be addressed. This conviction led to our decision to investigate the following research question and related hypothesis

Question: "Can disciplined experimentation reduce uncertainty in NPD in a fast changing environment?"

Hypothesis: it can, if two conditions are fulfilled:

First, that the experimentation is constructed in order to progressively test out and validate three variables, in particular

- Value - how the new product or service will create value by resolving a 'vivid' need (as opposed to a latent one), producing outcomes that outweigh the effort required.

- Growth - how the new product can be scaled up beyond the first group of pioneering customers, guaranteeing that the value created will also increase.

- Sustainability - how easily the organisation will adapt to the changes required to implement the new product and how easily competitors can replicate it 
Second, that disciplined experimentation entails two mutually reinforcing dimensions

- The use of creative experimentation techniques which exploit innovations in technology and process in order to maximise the number of experiments, while making them as inexpensive as possible through speed of execution

- Use of experimental analysis approaches, such as Design of Experiments (DoE) that maximise the learning from each experiment performed

In order to test the validity of our hypotheses the next step was to identify organisations that would be willing to participate in a long term study. We succeeded in engaging four organisations from industries as diverse as rail transportation (United Kingdom), animal health pharmaceuticals (United Kingdom), gas heating system manufacturing (Italy) and fashion (Italy) with whom we have worked for the last 18 months. This paper presents our preliminary findings.

\section{The Progressive Hypothesis}

The success of a newly developed product, defined as its ability to contribute to the achievement or sustaining of competitive advantage of the firm, relies on a set of hypotheses which need to be validated. A hypothesis, in business as in science, is an explanation or a proposition made on the basis of limited evidence which serves as the starting point for further investigation. Until proven true, hypotheses are just statements. The only way to prove their validity is to test them. Testing will either prove or disprove the validity of a hypothesis, but it will also provide insights about how the hypothesis could be refined or even replaced by a better one.

Just like a scientist in a laboratory, business executives should first make explicit the hypotheses behind the initiatives they wish to launch and then validate them through experiments. We propose, as stated before, that in the case of NPD there are three hypotheses that need to be validated progressively: first value, then growth and concluding with sustainability. As you move from each hypothesis to the next, the overall level of uncertainty reduces, but it is not until the new product has provided evidence for all three hypotheses that uncertainty will be significantly reduced, although never completely eliminated.

The first hypothesis is about Value, which involves explaining how the new product will create value by producing outcomes that outweigh the effort involved. Typical questions that need to be addressed are:

- What kind of problem does the new product solve?

- Who are the people facing this problem? How aware are they of the problem?

- Are they prepared to pay for someone to solve it?

- Will the price they are prepared to pay for the new product be sufficient to cover the cost of its development? 
The second hypothesis is about Growth. Here we must think through how the initiative can be scaled up beyond the first group of customers, guaranteeing that the value created will also increase sufficiently. The typical questions to be addressed are:

- Does the new product address the needs of a large enough group of people?

- Will the new product need to be changed or adapted for this enlarged group?

- How difficult and how costly would it be to scale-up to meet increased demand?

- What is needed for the new product to appeal to this larger group?

- Will the price need to be changed?

- How could we reach and engage a growing group of users? How much would this cost?

- Will the increase in users be reflected in increasing value creation i.e. will the increase in outcomes outstrip the increase of the cost of achieving such growth?

The last hypothesis is about Sustainability which has two mutually reinforcing facets. The first relates to the ease with which competitors can replicate the new product and the second concerns how easily the organisation itself will accept the changes required to implement the initiative. The typical questions for the first facet are:

- How easily can the competition imitate the new product or substitute it with another product? How long would it take?

- What kinds of barriers are there which will preserve the advantage?

- Are there other barriers we could create? How much would they cost?

And for the second facet:

- How will the organisation need to change to enable the new product to be implemented?

- Will the organisation be able to cope with such changes?

- Is there something about the initiative that we can adapt in order to make it more acceptable to the people and culture of the organisation? What impact would this adaptation have in terms of value creation?

By addressing these questions executives engaged in NPD will be able to decide whether the new product merits being moved forward. Furthermore, this approach will help to identify potentially serious flaws which require fixing before the initiative can be progressed.

\section{The Two Facets of Experimentation}

To get maximum benefit from experimentation, there must be clarity about which tests will be carried out, in which order, and the metrics which will be used to judge the outcome and decide whether or not the hypothesis has been proven. Many experimentation tools and techniques are available and new ones can always be 
developed, but the most important thing is to select the ones that are the most appropriate for the particular circumstances. The fitness for purpose of any technique will depend on the time and resources available, but the ideal should be something which is simple, quick and inexpensive.

In any experiment about new product development, managers and engineers separate an independent variable (the 'cause') from a dependent variable (the 'effect') and then manipulate the former in order to observe changes in the latter. The manipulation, followed by careful observation and analysis, then gives rise to learning about relationships between cause and effect, which can be applied or tested in other settings. For example, the weight or shape of a product can be manipulated to examine its effect on how easy it is for customers to use. Fear of failure can also be an inhibiting factor in the use of experimentation and hypothesis testing. Because of this, the importance of a company culture which encourages transparency and appropriate risk is underlined.

One of the key barriers to experimentation has always been the cost, since it has often been considered expensive in terms of the time involved and the effort expended. What has changed, particularly given the new technologies available, is that it is now possible to perform more experiments in an economically viable way while accelerating the drive towards a successful new product.

To overcome the cost constriction barrier, managers have essentially two choices:

- change the fundamental economics of experimentation through new creative processes and new innovative technologies

- try to get more out of each experiment by employing sophisticated statistical methods, which help to manipulate multiple variables in a single experiment while maintaining integrity in its data analysis

\subsection{Facet 1: Using Creative Processes and New Technologies to Increase the Number of Experiments}

New creative processes and new innovative technologies now enable more learning to be created more rapidly, and the outcomes can be incorporated in even more experiments at less expense. Examples can be found in:

Customer usage simulations. This involves the building of simple mock-up user interfaces (e.g. a website) to see if customers are interested in a particular value proposition, including the description of the product features, the price and even how the product works. This particular type of process has been exploited by the Lean Start Up and Design thinking approaches.

Computer modelling. Since 1945, when the first Monte Carlo based simulation was used to build a computer generated artificial world for the development of the hydrogen bomb, computer modelling has become an essential part of science. However, it is only with the dramatic increase in the availability of low cost computer power that computer modelling has become an everyday reality. Today, Artificial Intelligence (AI) packages or Computer Aided Design (CAD) can in many cases be used instead of physical experiments in design and market testing. 3D CAD has in many instances now eliminated almost completely the need for physical prototypes. Many organisations using 'big data' can use a computer simulation to assess the likely response of customers to, say, a change in price. 


\subsection{Facet 2: Accelerating Learning through Experimentation}

When all relevant variables are known, formal statistical techniques and protocols allow for the most efficient design and analysis of experiments. These techniques are used widely in many fields of process and product optimisation today and can be traced to the first half of the $21^{\text {st }}$ century when the statistician and geneticist Sir Ronald Fisher first applied them to agricultural and biological science. The techniques he pioneered have become the foundation of what today we call Design of Experiments (DoE)

Design of Experiments (DoE) is a statistical method of establishing which variables are important in a process, and the conditions under which these variables should work to optimize that process (Ilzarbe et al. 2008). Methods from the field of DoE have been applied to quality control problems in many engineering fields for several decades (Kuhn, Reilly 2002) and according to Ilzarbe et al (2008) many scientists and statisticians have contributed to DoE development and to its application in different fields.

Thomke (2003) identifies seven factors (see Table 1) that affect the ability to learn through experimentation which are: fidelity, cost, iteration time, capacity, sequential and parallel strategies, signal to noise ratio and type of experiment.

Table 1: Thomke's (2003) Factors that Affect the Learning by Experimentation

\begin{tabular}{|l|l|}
\hline Factor & Definition \\
\hline Fidelity of experiments & $\begin{array}{l}\text { The degree to which a model and its testing conditions } \\
\text { represent a final product, process, or service under actual user } \\
\text { conditions }\end{array}$ \\
\hline Cost of experiments & $\begin{array}{l}\text { The total cost of designing, building, running, and analysing } \\
\text { an experiment, including expenses for prototypes, laboratory } \\
\text { use, etc. }\end{array}$ \\
\hline Iteration time & $\begin{array}{l}\text { The time from planning the experiment to when the analysed } \\
\text { results are available and used for planning another reiteration }\end{array}$ \\
\hline Capacity & $\begin{array}{l}\text { The number of same fidelity experiments that can be carried } \\
\text { out per unit of time }\end{array}$ \\
\hline Strategy & $\begin{array}{l}\text { The extent to which the experiments are run in parallel or } \\
\text { series }\end{array}$ \\
\hline Signal-to-noise ratio & $\begin{array}{l}\text { The extent to which the variable of interest is obscured by the } \\
\text { 'noise' of too many other variables }\end{array}$ \\
\hline Type of experiment & $\begin{array}{l}\text { The degree of variable manipulation (incremental versus } \\
\text { radical changes) }\end{array}$ \\
\hline
\end{tabular}

\section{Early Evidence from Field Work}

As part of a 3 year study we have worked with a number of multinational organisations based in the UK and Italy all of which carry out a considerable part of their business outside their domestic markets. The sectors covered are fashion (production and retailing), heating systems (electric and gas), animal health pharmaceuticals and rail transportation.

As part of the research we have been allowed to work alongside the NPD teams as they attempt to successfully launch new products. A successful launch is one where within a reasonable amount of time (always less than 24 months) the product 
achieves volumes and revenue that are significant for the organisation, contributing to the bottom line and ultimately to the sustaining of their firm's competitive advantage

At the time of writing we have started work with all four multinationals, but because of the different stages of progress of the projects we have chosen, in this paper, to concentrate on just two of the cases: those of the fashion house and the heating systems manufacturer.

\subsection{Fashion House}

The fashion house is a fully integrated textile company with over a century of history and many innovations to its name. They were the first to introduce a certain type of dyeing, which allows fast and very economical production and to introduce large scale fully automated cutting plants. They were also among the first to launch successfully the 'fast fashion' business model made famous by the likes of ZARA, which quickly became the company's main driver of growth and profitability.

Unfortunately, in recent years the performance of the fast fashion division declined dramatically. A succession of management changes failed to reverse this decline. Late in 2013 a new management team, with considerable experience in turnarounds was called in. This new team invited us to work with the company, and in particular with the NPD team. They understood that the company's core challenge, which would unlock the turnaround, was to return to its tradition of innovation.

Their products suffered from two problems. First, they were coming to market much later than competitor's products and and therefore, in the seasonal and rapidly changing world of fashion, it was impossible to command prices that would guarantee profitability ('by the time the products were out it was time for the heavy discount sales'). Secondly, many of their products were not in line with customer tastes, leading to high levels of unwanted stock.

The management decided to completely overhaul the NPD process by introducing a new system called Marketeyes, which introduced the discipline of experimentation to the heart of NPD. Marketeyes is a type of social workflow management system that allows an idea for a new product to go through a set of rapid experiments, which reduce the risk that the product will not succeed in the market. These experiments range from a simple and quick survey about the idea in the form of a professionally designed sketch of the garment with details of the price points and the type of material, that within 2 hours is sent to over 3000 shop assistants who give their view about the product, to a pre-ordering e-commerce facility that allows carefully selected 'predictive' customers (who historically have purchased garments that turned out to be successful) to view and pre-order products. The results of all the experiments are analysed through statistical techniques that provide insights about whether the product is likely to be successful and also the size of the potential success, in terms of volume and value of sales.

Marketeyes keeps track of all the experiments and provides hard evidence of what does and what does not work as well as what can be changed to increase the chances of success. This has accelerated the process to the point where an informed decision as to whether to launch a new garment can be made within 7 working days. The process is not only speedy but also very discriminating, since many products that were initially thought to be potential blockbusters have been stopped 
or launched with a reduced range. Marketeyes is accessible and used by most of the divisions of the organisation from product design to supply chain, from management control to shop assistants, which enables the fashion house to spread knowledge about new products, as well as invite suggestions for new products.

Based on a recent spring collection, early evidence suggests that the products launched using Marketeyes perform twice as well, in terms of 'in season sell', compared with the products launched using the traditional NPD system.

From the evidence gathered so far it seems that, thanks to fast experimentation and the learning gained from the analysis of the experimental results, Marketeyes provides a very efficient way to validate the value and growth hypothesis. It is too early to fully assess the sustainability hypothesis as only one aspect of sustainability - the ability of the company to adapt to the new product - can currently be examined. The competition has not yet reacted, because the size of the product portfolio produced using Marketeyes is still very small.

\subsection{Gas and Electric Heating Systems}

The company we are working with is a multinational, serving over 50 countries and with production facilities in more than half a dozen countries, specialising in the design, manufacture, and distribution of electric and gas heating systems. It has a history of successfully developing good quality, mid-range, technically sophisticated products, all in its traditional core business. This has given the company the reputation of one of the best value for money brands in its industry in the world.

The company has, over the last 15 years, installed a very large number of heating systems which will soon be due for replacement. The biggest challenge for the company is how to ensure that its own products will be chosen to replace or repair the aging systems rather than those supplied by their competitors. . This is complicated by the fact that its products are distributed mainly through independent installers and service centres and it is therefore these independent businesses who have the direct relationship with the users of the systems. However, most of the independent installers and service centres distribute and fit systems from a wide range of manufacturers and have proven to have very little long term loyalty to any of the brands they sell. Their choice of brand tends to hinge upon the current levels of commission and the likelihood of them being awarded a contract for maintaining the installations they carry out. Furthermore, in recent years new technology players such as Nest Labs with products like the 'learning thermostat', have entered the space from adjacent markets, introducing devices that are providing some of the features of traditional heating systems.

Given this context, in early 2013 the company decided to launch a project to develop a device that would allow remote connectivity with heating systems, as well as a wide array of other features, such as automatic optimisation of temperature and safety alerts. The purpose was to combine, in one device, the needs, or 'Job to Be Done', of three different actors or stakeholders; the end users needing to keep the temperature of their houses under (remote) control and have problems diagnosed by service centres, the service centres needing to streamline their operation by using remote diagnosis to tell them what needs to be done before the engineer makes a service call, and finally the Company itself which needed a 
sort of 'field laboratory' to provide better information about, for instance, how its systems were performing and what parts needed replacement.

Initially, the project was driven by the $\mathrm{R} \& \mathrm{D}$ and engineering divisions who presented a business case to the Board which required a multi-million Euro investment for designing and deploying the product. The Board was not convinced. Several years before, a similar project (with a similar budget) not only failed dramatically but also caused difficulties with the company's distribution network. In the light of this salutary experience the Board was reluctant to take another sizeable risk. As a result they decided to change their approach. They asked the marketing team to investigate how the level of risk could be reduced.

The marketing team, working closely with our researchers, started by carefully identifying the main needs, or Job to Be Done, of each actor and the cost of the best currently available solution that would meet these 'vivid' needs (e.g. remotely controlled thermostat, plus a special maintenance contract). Based on this research the team produced a high quality brochure and a non-functional but graphically complete app for a device that presented the product as if it already existed, including information on price, key features and pictures of what the device would look like. Armed with the brochure and the app, the Company approached a number of installer-service centres selected on the basis of their openness to innovation. Each service centre was told that the product would be launched in 12 months but, as a valued partner, they were being given the opportunity to pre-order. Unlike most traditional market research approaches, the Company asked service centres who liked the product to actually sign an order, thereby capturing not just intention to buy, but actual sales.

To their surprise, the first few sales meetings were a disaster. The potential customers were very negative about a number of aspects of the product including the design, the price and the main features. Undiscouraged, the team used this valuable, if somewhat painful, feedback to 'pivot': changing their working hypotheses to accommodate this new data. But they were not yet ready to go back to their R\&D colleagues to commission the actual product. Instead, guided by the insights generated by their research the team kept on using this approach to refine their understanding of what the product should be like. After another half-dozen iterations of the process: varying the features, price, and even design and listening carefully to the feedback, the team was leaving most of its sales meetings with sizeable pre-orders. They now knew that the product they visualised was one which would sell. The Board was presented with the findings of the team and the R\&D department, after some persuasion, committed to create a prototype of a device which was simpler and easier to develop than originally envisaged.

Although the marketing team had already significantly reduced the level of risk in creating and launching the new device, they knew that more could be done. They decided to run the same type of experiment directly with end customers: the people that would eventually have the device fitted in their homes. Working with service centres, the team put up display stands in major department stores which showcased the product to passing shoppers using pictures, leaflets and a very simple video cartoon. The comments received from prospective customers provided another rich source of information and triggered further 'pivots' and rapid design changes. For example, the team had hypothesised that they could rely on domestic Wi-Fi to transmit information from the device, given the high penetration of $\mathrm{Wi}-\mathrm{Fi}$ in Italian households. However, their store-based research revealed that around half the 
people having Wi-Fi at home, switch it off overnight to save energy or because of worries about the health risks of electro-magnetic fields. As a result many people would prefer to buy a GPRS version. Using this sort of feedback changes were able to made to the price, features and presentation of the product at a stage when such alterations could be made quickly, cheaply and without embarrassment to the Company.

The entire process took approximately 10 weeks from start to finish. It enabled the Company, at least theoretically, to avoid a costly failure with a product that would not have been well received. Instead, they now have a product that has a much greater chances of success. While this achievement alone would have justified the project, there were also a number of other benefits. Participating in the project allowed people across the organisation to understand the biases they had about what customers wanted and valued; biases that were often incorrect. The experience also had a strong impact on two aspects of how the company would work in future. First, it had the effect of accelerating the product development process as R\&D staff had been forced to use unconventional methods such as 3D rendering to prototype and test their creations. Secondly, it led to the development of a 'Go to Market' model built on a clearer understanding of the tools and processes required by the salesforce to sell such an innovative product.

\section{Discussion and Lessons Learned}

The three major lessons learned so far from this research are:

- Companies should carry out as many experiments as possible at an early stage of the NPD process. This will reduce the overall time to market as well as the cost of designing and launching a new product.

- It is vital to have the courage to abandon or put on ice any new product if the evidence in support of the product from the experiments is not sufficiently strong.

- There is a limit to the amount of uncertainty which can be removed through planned and deliberate experimentation. Even after the launch, it is best to consider all events and experiences as an extension of the research process and take note of the outcomes. The final lesson learned is also a note of caution. Many people mistakenly assume that experimentation is the same as running a pilot phase.

However, we would argue that experimentation is very different from running a pilot for the following reasons:

- Pilots are usually the prelaunch of an initiative that has already been developed, with the aim of the pilot being to prepare for full implementation. Experimentation, in contrast, is a process used to develop a new product and ensure that it meets the criteria of value, growth and sustainability.

- In a pilot, the final or advanced version of the new product is tested, albeit on a small scale. This limits its usefulness as a means of testing because if it goes wrong it is hard to say which particular aspect led to the failure. As a result, areas for improvement cannot be accurately 
pinpointed. Experimentation is a progressive process, which scrutinises different aspects of a new product in turn, and therefore is much more likely to highlight exactly what is wrong, or right, about the new product.

- Although pilots are often carried out with the intention of smoothing the process of change within the organisation, if they are presented as a fait accompli - a predetermined new product from the top - they may have the opposite effect and build resistance. In contrast, experimentation can be done as a participative exercise, which allows staff to contribute to and understand the development of a new product, process or service. Involving staff in this way not only leads to a better developed initiative, it also means they are more likely to support its implementation

\section{Limitations and Further Research}

The research reported in this paper has of necessity been limited to two case studies. From our experience so far the use of the framework suggested in this paper offers a means to improve the NPD process in terms of selecting appropriate new products that fully satisfy customer needs, speed of NPD delivery, and ultimately cost. Only through the continued application of the methods described can the framework be further tested, which will, of course, take time. However, the more people who apply the approach the sooner we will understand its impact more fully. As in the NPD approach we are recommending, we are looking for evidence to refine the framework.

Applying the methods we have described to work in tandem with other methodological processes could offer improved performance of those methods and raise the success rate in selecting the right product for the right customer at the right time and at the right price. We would argue that disciplined experimentation could prove a useful addition to other NPD processes, provided it is conducted correctly.

\section{Bibliography}

Amabile Teresa M. (1997) Motivating Creativity in Organizations: On Doing What you Love and Loving What you Do, California Management Review, vol. 40, n. 1, pp. 39-58. http://dx.doi.org/10.2307/41165921

Barczak Gloria, Griffin Abbie, Kahn Kenneth B. (2009) Trends and Drivers of Success in Npd Practices: Results of the 2003 Pdma Best Practices Study, Journal of Product Innovation Management, vol. 26, n. 1, pp. 3-23. http://dx.doi.org/10.1111/j.1540-5885.2009.00331.x

Bisgaard Søren (1992) Industrial Use of Statistically Designed Experiments: Case Study References and Some Historical Anecdotes, Quality Engineering, vol. 4, n. 4, pp. 547-562. http://dx.doi.org/10.1080/08982119208918936

Brondoni Silvio M. (2012) Innovation and Imitation: Corporate Strategies for Global Competition, Symphonya. Emerging Issues in Management (symphonya.unimib.it), n. 1, pp. 10-24 http://dx.doi.org/10.4468/2012.1.02brondoni

Brondoni Silvio M. (2009) Market-Driven Management, Competitive Customer Value and Global Network, Symphonya. Emerging Issues in Management (symphonya.unimib.it), n. 1, pp. 8-25. http://dx.doi.org/10.4468/2009.1.02brondoni 
Brondoni Silvio M. (2008) Ouverture de 'Market-Driven Management and Global Markets - 2', Symphonya. Emerging Issues in Management (symphonya.unimib.it), n. 2, pp. 1-12.

http://dx.doi.org/10.4468/2008.2.01ouverture

Buchanan Richard (1992) Wicked Problems in Design Thinking, Design Issues,vol. 8, n. 2, pp. 5-21. http://dx.doi.org/10.2307/1511637

Castellion George, Markham Stephen K. (2013) Perspective: New Product Failure Rates: Influence of Argumentum ad Populum and Self-Interest, Journal of Product Innovation Management, vol. 30, n. 5, pp. 976-979. http://dx.doi.org/10.1111/j.1540-5885.2012.01009.x

Cook Stephen C. (1989) Applying Critical Chain to Improve the Management of Uncertainty in Projects, MBA and MSc Thesis, Sloan School of Management and the Department of Electrical Engineering on May 9.

Cooper Brant, Vlaskovits Patrick (2010) The Entrepreneur's Guide to Customer Development: A cheat sheet to The Four Steps to the Epiphany. s.l. Cooper-Vlaskovits.

Cooper Robert G., Kleinschmidt Elko J. (1986) An lnvestigation into the New Product Process: Steps, Deficiencies and Impact, Journal of Product Innovation Management, vol. 3, n. 2, pp. 7185

http://dx.doi.org/10.1111/1540-5885.320071

Cooper Robert G., Kleinschmidt Elko J. (1987) New Products: What Separates Winners from Losers, Journal of Product Innovation Management, vol. 4, n. 3, pp. 169-184. http://dx.doi.org/10.1111/1540-5885.430169

Cooper Robert G., Kleinschmidt Elko J. (1990) New Products: The Key Factors in Succes, American Marketing Assoc., Chicago.

Cooper Robert G., Kleinschmidt Elko J. (1991) New Product Processes at Leading Industrial Firm, Industrial Marketing Management, vol. 10, n. 2, pp. 137-147. http://dx.doi.org/10.1016/0019-8501(91)90032-B

Cooper Robert G., Kleinschmidt Elko J. (1993) Screening new products for potential winners, Long Range Planning, vol. 26, n. 6, pp. 74-81. http://dx.doi.org/10.1016/0024-6301(93)90208-W

Cooper Robert G., Edgett Scott J., Kleinschmidt Elko J. (1998) Best Practices for Managing R\&D Portfolios, Research - Technology-Management, vol. 41, n. 4, pp. 20-33.

Cooper Robert G., Edgett Scott J., Kleinschmidt Elko J. (1997a) Portfolio Management in New Product Development: Lessons From the Leaders-Part I, Research - Technology Management, vol. 40, n. 5, pp. 16-28.

Cooper Robert G., Edgett, Scott, \& Kleinschmidt, Elko J. (1997b) Portfolio Management in New Product Development: Lessons from the Leaders-Part II, Research - Technology Management, vol. 40, n. 6, pp. 43-52.

Cooper Robert G., Edgett Scott, Kleinschmidt Elko J. (2000) New problems, new solutions: Making portfolio management more effective, Research - Technology Management, vol. 43, n. 2, pp. 1833.

Cooper Robert G. (2008) Perspective: The Stage-Gate Idea-to-Launch Process - Update, What's New, and NexGen Systems, The Journal of Product Innovation Management, vol. 25, n. 3, pp. 213-232. http://dx.doi.org/ 10.1111/j.1540-5885.2008.00296.x

Cormican Kathryn, O'Sullivan David (2004) Auditing Best Practice for Effective Product Innovation Management, Technovation, vol. 24, n. 10, pp. 819-29.

http://dx.doi.org/10.1016/S0166-4972(03)00013-0

Davidson Jeffrey M., Clamen Allen, Karol Robin A. (1999) Learning from the Best New Product Developers, Research-Technology Management, vol. 42, n. 4, pp. 12-18.

DeCusatis Casimer (2008) Creating, Growing and Sustaining Efficient Innovation Teams, Creativity and Innovation Management, vol. 17, n. 2, pp. 155-164. http://dx.doi.org/10.1111/j.1467-8691.2008.00478.x

Ertas Atila, Jones Jesse C. (1996) The Engineering Design Process. 2nd ed. New York, N.Y.: John Wiley \& Sons, Inc.

Fixson Sebastian K. (2009) Teaching Innovation through Interdisciplinary Courses and Programmes in Product Design and Development: An Analysis at 16 US Schools, Creativity and Innovation Management, vol. 18, n. 3, pp. 199-208. http://dx.doi.org/10.1111/j.1467-8691.2009.00523.x 
Goldratt Eliyahu H. (1997) Critical Chain, North River Press, Great Barrington.

Hall Nicholas G. (2012) Project Management: Recent Developments and Research Opportunities, Journal of System Science and System Engineering, vol. 21, n. 2, pp. 129-143. http://dx.doi.org/10.1007/s11518-012-5190-5

Highsmith Jim (2002) What is Agile Software Development? Crosstalk, Journal of the Defense Software Engineering, vol. 15, n. 10, pp. 4-9.

Highsmith Jim (2004) Agile Project Management: Creating Innovative Products, Addison-Wesley Professional, Indiana.

Hustad Thomas P. (1977) Approaches to the Teaching of Product Development and Management, Product Development Management Association, 113.

Ilzarbe Laura, Alvarez Maria J., Viles Elisabeth, Tanco Martin (2008) Practical Applications of Design of Experiments in the Field of Engineering: A Bibliographical Review, Quality and Reliability Engineering International, vol. 24, n. 4, pp. 417-428. http://dx.doi.org/ 10.1002/qre.909

Jenner Stephen (2007) Gates with Teeth: Implementing a Centre of Excellence for Investment Decisions, Paper Presented at the First International Stage-Gate Conference, February 20-21, St. Petersburg, FL.

Kahn Kenneth B., Barczak Gloria, Nicholas John, Ledwith Ann, Perks Helen (2012) An Examination of New Product Development Best Practice, Journal of Product Innovation Management, vol. 29, n. 2, pp. 180-192. http://dx.doi.org/10.1111/j.1540-5885.2011.00888.x

Kelley Tom (2001) The Art of Innovation: Lessons in Creativity from IDEO, America's Leading Design Firm, Currency Books, New York.

Kuhn D. Richard, Reilly Michael J. (2002) An Investigation of the Applicability of Design of Experiments to Software Testing, 27th NASA/IEEE Software Engineering Workshop, NASA Goddard Space Flight Centre, 4-6 December.

http://dx.doi.org/10.1109/SEW.2002.1199454

Leach Larry P., (1999) Critical Chain Project Management Improves Project Management, Project Management Journal, vol. 30, n. 2, pp. 39-51.

Loch Christoph (2000) Tailoring Product Development to Strategy: Case of European Technology Manufacturer, European Management Journal, vol. 18, n. 3, pp. 246-58. http://dx.doi.org/10.1016/S0263-2373(00)00007-4

Martin Roger L. (2009) The Design of Business: Why Design Thinking is the Next Competitive Advantage, Harvard Business Press, Boston.

Morris Peter W. G. (1990) The Strategic Management of Projects, Technology in Society, vol. 12, $\mathrm{n}$. 2, pp. 197-215. http://dx.doi.org/10.1016/0160-791X(90)90008-Z

Mueller Roland M., Thoring Katja, (2012) Design Thinking versus Lean Startup: A Comparison of Two User-Driven Innovation Strategies, International Design Management Research Conference, August 8-9, Boston, USA

Onyemar Vincent, Pesquera Martha R., Ali Abdul (2013) What Entrepreneurs Get Wrong, Harvard Business Review, May 2-7.

Ries Eric (2011) The Lean Start-Up: How Today's Entrepreneurs Use Continuous Innovation to Create Radically Successful Businesses, Crown Business, New York.

Rittel Horst W. J. (1972) On the Planning Crisis: Systems Analysis of the First And Second Generations, Bedriftsokonomen, vol. 8, pp. 390-396.

Simon Herbert (1969) The Sciences of the Artificial, MIT Press, Cambridge.

Smith Preston G., Reinertsen Donald G. (1998) Developing Products in Half the Time - New Rules, New Tools, John Wiley \& Sons, New York.

Thomke Stefan H. (2003) Experimentation Matters - Unlocking the Potential of New Technologies for Innovation, Harvard Business School Press Boston. 